\title{
Proceeding
}

6th ISPAS International Workshop, 22-23 March 2016. International Society of Performance Analysis of Sport. Carlow, Ireland.

\section{Performance improvement through motor imagery study of the case in artistic gymnastics}

\author{
SALVATORE NAPOLITANO \\ University of Naples "Parthenope", Naples, Italy
}

\begin{abstract}
The motor imagery is a cognitive process of mental simulation of actions in absence of movement. There are two methods to improve skills learning trough motor imagery: in first person and in third person. The biological basis on which the motor imagery theory is founded by mirror neurons. The aim wants to evaluate the effects of motor imagery practice in training, so it verifies the effects on the skills. The method is experimental and it consists of two steps subsequently. To administrate the questionnaire at athletes in order to evaluate the perception of own skill, called round-off flic, and then to compare their perception with the evaluation of Italian federation of artistic gymnastics method. The data will be being compared with those of judge/technician. By the data there is a more effective internal evaluation and also an improvement in the performance on about $80 \%$ of the gymnasts that performed the round-off flic. Interpretation of data concerning evaluation of others emerged a lower outside awareness of the skills that is looked. The innovative aspect of this study is the use of hetero-evaluation tool. It is rarely used, but the data show improvements in the performance and ability to evaluate, after using for 5 months of this methodology. Another innovative aspect is the use of motor imagery in the third person. Finally, there's and improvements learnings for about $80 \%$. So, providing the athletes and trainers could use practice of motor imagery as a possible application for the improvement of the performance. Key words: PERFORMANCE IMPROVEMENT, MOTOR IMAGERY, ARTISTIC GYMNASTICS.
\end{abstract}

Cite this article as:

Napolitano, S. (2017). Performance improvement through motor imagery study of the case in artistic gymnastics. Journal of Human Sport and Exercise, 12(2proc), S508-S513. doi:https://doi.org/10.14198/jhse.2017.12.Proc2.04

Corresponding author. University of Naples "Parthenope", Department Physical Education and Wellness, Naples, Italy.

E-mail: salvatorenapolitano1@alice.it

6th ISPAS International Workshop, 22-23 March 2016. International Society of Performance Analysis of Sport. Carlow, Ireland. JOURNAL OF HUMAN SPORT \& EXERCISE ISSN 1988-5202

(c) Faculty of Education. University of Alicante

doi:10.14198/jhse.2017.12.Proc2.04

S508 | 2017| Proc2 | VOLUME 12

C 2017 University of Alicante 


\section{INTRODUCTION}

The motor imagery is a cognitive process of mental simulation of an action in the absence of physical movement. [1]. MI was deeply investigated also by Marc Jeannerod. One of the most scientist about the neurological process. He had lived between 1935 and 2011, its scientific life was entirely dedicated at neurology and neurophysiology, as well as other Scientifics about cognitive neuroscience and experimental psychology are interested. Specially, the mechanisms underpinning motor control, motor cognition are investigated by Decety in 1996, Driskell and Copper in 1994, Gallese and Rizzolatti between 1996-2012, Lafleur in 2002, Sanders in 2004. It also defined as a state of general activation during which a person feels himself to perform an action. The motor imagery should be distinguished from mental practice, the first refers to the cognitive process while, the second refers to the process of mental training that takes advantage of the first process. There are two types of motor imagery: in first-person and in third-person. In first person mode, the subject imagines himself to perform an action but not in the sense of seeing himself as an external or reflected image, in the sense to see what he would see, if he performed a movement and at the same time feel emotions, excitation, stress and changes of arousal. In third person mode, the person sees himself or another person as an external image, as with the use of a camera. The most effective for learning is that firstperson. Numerous studies have shown that the performance is optimized through the cognitive process of motor imagery. During the motor imagery the cerebral areas of the pre-motor cortex, the same which a muscular contraction would put in action, are activated. The pre-motor cortex is responsible for complex sequences of movements and selects them in response to a stimulus. The pre-motor cortex is located in front of the primary motor cortex and laterally on the surface of the frontal lobe.

The execution and imagination activate the same regions of the cerebellum, basal ganglia and motor cortex. All this is possible thanks to mirror neurons which are the biological basis on which is based the motor imagery. Mirror neurons are a class of neurons which are activated when we make a move and when we observe it, as if the observer did the movement [2]. Mirror neurons were discovered in the 90's by a group of researchers in a macaque, group coordinator is Giacomo Rizzolatti. In 1995, the same group of researchers demonstrated the existence of a neuronal group, similar to that of macaques, also in man. Mirror neurons have been found in the pre-motor cortex and the parietal lobe, area to which deputed only motor function and not the cognitive function. The activation of mirror neurons allows to map on the same nervous substrate actions performed and observed or imagined. In this way, you create an internal image released from execution. [3]. Mirror neurons are a particular class of visual-motor neurons which allows to learn and optimize a motor gesture without executing it. Mirror neurons represent the space of internal sharing that allows us to imitate, learn and understand the intentions of motor events. The ability to create an intersubjective space which is then shared with the world is connected to the role played by embodied simulation, neuro-scientifically based on mirror neurons. [4]. The study aims to evaluate the potential benefits of motor imagery on a group of gymnasts practicing gymnastics, especially for the rond off flick.

The artistic gymnastics is a sport of precision and the movements are complex, then it uses the abilities closed skills serial type, skills that are used in stable environments consist of a number of discrete skills are placed in sequence to form a more complex and protracted movement; as rond off flick. The rond off is like the wheel but at half movement the legs join. The flick is often performed after the rond off and consists of two times: the first time you push whit the legs and then you put your hands back to the ground, in the second time you push by the upper limbs and then return to the position departure. The artistic gymnastics uses the model of closed-loop control with the use of feedback [5]. In sport activity, the phenomenon of the influence of mental aspects run usually. In the School of Sport, Health, and Exercise Sciences at Bangor University, the project proposal module is worth 10 credits and comprises of a verbal presentation and written proposal. 
Nichola Callow and Ross Roberts propose the module project is worth 10 credits and comprises of a verbal presentation and written proposal on sport activity. In physical education and sport medicine was realized many studies about the mental function and the results show the preeminent position on imagination and its pattern in movement and performance [6]. Curry, L. A and Maniar, S. D. researched in academic course combining psychological skills training and life skills education for university students and student-athletes [7]. The aim of this study is to apply the tool of the evaluation by oneself, by others and by judge according to a specific standard test. Two imagery measures (VMIQ and MIQ-R) were used to capture whether the selfmodeling video would influence competitive divers' imagery vividness and ability.

\section{MATERIAL AND METHODS}

The method used for this study is an experimental one and it consists of two steps: the first step is a direct experimental type while the second is an indirect experimental type. The means used in the first part of the study is the questionnaire (here attached) formed by three columns and different items. The first columns concern the evaluation by oneself, the second one concerns the oneself evaluation of others and the third one the valuation by a judge/technician. The participants are asked to evaluate the sensation of their own motor act and then their mate's one in accordance with valuation methods of Italian federation of artistic gymnastics. The data will be compared with those of judge/technician. The means used in the second part of the study is the video recording. The participants are given the vision of their own motor gesture and then the others' one, previously recorded, and the video will be stopped before the gesture ends. The participants are asked a starting evaluation of external type, which will be compared with those of the judge/technician and at last a final forecast of the performance result will be asked. The forecast will be compared with the final results (internal, external and judge/technician) and collective according to an appropriate statistical pattern. The sample that are part of the experiment consists of two athletes to medium-high level practicing gymnastics for not less than 5 years of age between 12 and 15 years. The athletes before beginning the training, they will be educated on the modalities cognitive and practices that must be performed (MI in the first and third person) and the means by which they are evaluated. The research hypothesis is to provide a standard training feasible on a large scale to train the cognitive and physical abilities of an athlete and provide a support tool in the race in order to improve performance, optimize time and to reduce the margin of error.

\section{RESULTS}

The results are based on the assumption neuro-scientific by the activity of mirror neurons that allow you to use the same nervous substrate for actions performed or observed, or thought. Interpretation of data concerning evaluation of others, namely evaluation of the athletes towards the companions emerged a lower outside awareness of the motor act that is looked. However, there are consistency and improvements for about $80 \%$ of the ratings that shows how the training of motor imagery in the first person may be accompanied by one in the third person. In order to contribute to improving the performance in training and the race since it the same neuronal synapses are activated for both actions you thought or observed both for themselves (ie in the first person), and other (ie in the third person). In the table 1 and 2 there are evaluation of the athlete 1 and 2 . In the table 3 there are evaluation by judge. In the figure 1 there is the comparison between heteroevaluations and evaluation of the judge. As can be seen from Figure 1, the evaluation by athletes have not assonance with those by the judge. However, we note an improvement of performance and of skill to evaluate in the second part of study (month 4 and 5). First the athletes tend to underestimate the performance then there is more consistency. 
Table 1. Hetero-evaluation by the athlete 1.

\begin{tabular}{|c|c|c|}
\hline & Athlete 1 & Athlete 2 \\
\hline 1 ROND- OFF FLICK & & 3,5 \\
\hline 2 ROND- OFF FLICK & & 3 \\
\hline 3 ROND- OFF FLICK & & 4,5 \\
\hline 4 ROND- OFF FLICK & & 4,5 \\
\hline 5 ROND- OFF FLICK & & 5,5 \\
\hline 6 ROND- OFF FLICK & & 8,6 \\
\hline 7 ROND- OFF FLICK & & 8.5 \\
\hline 8 ROND- OFF FLICK & & 7 \\
\hline 9 ROND- OFF FLICK & & 8,2 \\
\hline 10 ROND- OFF FLICK & & 7,9 \\
\hline 11 ROND- OFF FLICK & & 8,2 \\
\hline
\end{tabular}

Table 2. Hetero-evaluation by the athlete 2 .

\begin{tabular}{|c|c|c|}
\hline 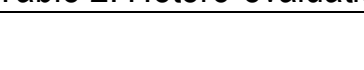 & Athlete 2 & Athlete 1 \\
\hline 1 ROND- OFF FLICK & & 3 \\
\hline 2 ROND- OFF FLICK & & 4 \\
\hline 3 ROND- OFF FLICK & & 3,5 \\
\hline 4 ROND- OFF FLICK & & 4,5 \\
\hline 5 ROND- OFF FLICK & & 6,5 \\
\hline 6 ROND- OFF FLICK & & 6 \\
\hline 7 ROND- OFF FLICK & & 6 \\
\hline 8 ROND- OFF FLICK & & 7,5 \\
\hline 9 ROND- OFF FLICK & & 7,5 \\
\hline 10 ROND- OFF FLICK & & 8,2 \\
\hline 11 ROND- OFF FLICK & & 9 \\
\hline
\end{tabular}

Table 3. Evaluation by judge.

\begin{tabular}{lll}
\hline & Athlete 1 & Athlete 2 \\
\hline 1 ROND- OFF FLICK & 6.3 & 6,5 \\
2 ROND- OFF FLICK & 6.2 & 7,9 \\
3 ROND- OFF FLICK & 6.5 & 6 \\
4 ROND- OFF FLICK & 6,9 & 7.5 \\
5 ROND- OFF FLICK & 7 & 7 \\
6 ROND- OFF FLICK & 7,5 & 7,5 \\
7 ROND- OFF FLICK & 8 & 7.8 \\
8 ROND- OFF FLICK & 8,3 & 7,9 \\
9 ROND- OFF FLICK & 7,9 & 7,5 \\
10 ROND- OFF FLICK & 8 & 8 \\
11 ROND- OFF FLICK & 8,5 & 8.5 \\
\hline
\end{tabular}




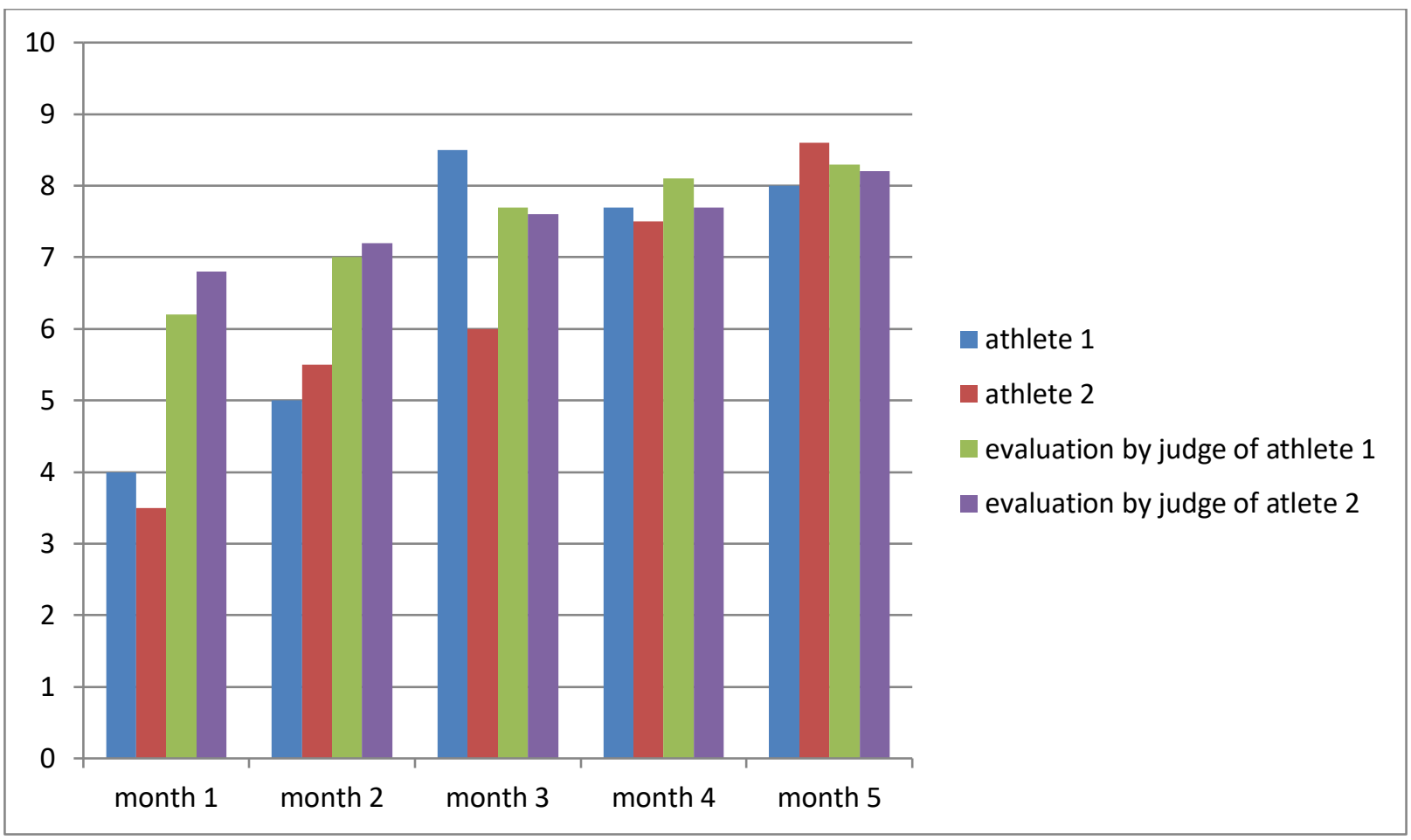

Figure 1. Comparison between hetero-evaluations and evaluation of the judge.

\section{DISCUSSION}

The innovative aspect of this study is the use of hetero-evaluation tool. It is rarely used, but the data show improvements in the performance and ability to evaluate, after using for 5 months of this methodology. Another innovative aspect is the use of motor imagery in the third person. Also it is rarely used. These tools use the same nervous substrate used for movements executed, thought or observed. In this way stimulates neural connections and improving performance, racing and training. Awareness improves in young athletes too. Study provides a valuable tool for improving performance, minimally but it is a great starting point. In sport activity the phenomenon of the influence of mental aspects run usually. In the School of Sport, Health, and Exercise Sciences at Bangor University, the project proposal module is worth 10 credits and comprises of a verbal presentation and written proposal. Nichola Callow and Ross Roberts propose the module project is worth 10 credits and comprises of a verbal presentation and written proposal on sport activity. In physical education and sport medicine was realized many studies about the mental function and the results show the preeminent position on imagination and its pattern in movement and performance (Astin et al. 2003). Curry, L. A and Maniar, S. D. researched in academic course combining psychological skills training and life skills education for university students and student-athletes.

\section{CONCLUSIONS}

In this study two basic aspects of the sports performance are examined: the motor execution and the motor imagine. Both share the same neuro-motor mechanism: the motor imagery. Concerning the woman artistic gymnastics, it can be useful during the training and the race. It gives a pattern of action in first person which allow to concentrate all emotions, sensations and mood of a motor action without moving a muscle but putting all the neuro-motor proceeding in action. The motor imagery is a natural ability and so if trained, it is useful for the performance strengthening. So providing the athletes and trainers of a means which uses the motor 
imagery as a possible application for the improvement of the performance is very ambitions. So in conclusion, the study aims to provide a standard training feasible on a large scale to train the cognitive and physical abilities of an athlete and provide a support tool in the race in order to improve performance, optimize time and to reduce the margin of error. This tool aims to be refined with the use of notational video methods that will allow the analysis of quantitative aspects (such as the strength, the explosive strength, the resistance etc.) other than those quality of the internal and external evaluation, in relation to the effective role played by the motor imagery widely used for sports that use closed skills and therefore useful for artistic gymnastics. The study aims to use the motor imagery in first person (much used) and in the third person (less used) for the training of gymnasts practicing artistic gymnastics. The study also in some small way confirms the usefulness of using the tool of motor imagery in third person.

\section{REFERENCES}

1. Jeannerod, M. (2006). Motor cognition: What actions tell the Self. Oxford University Press.

2. Rizzolatti, G., \& Sinigaglia, C. (2006). So quel che fai. Il cervello che agisce e i neuroni specchio, Raffaello Cortina Editore, Milano.

3. Jeannerod, M. (2002a). Le Cerveau intime. Paris: Editions Odile Jacob.

4. Jeannerod, M. (2002b). La Nature de l'esprit. Paris: Editions Odile Jacob.

5. Astin, J. A., Shapiro, S. L., Eisenberg, D. M., \& Forys, K. L. (2003). Mind-body medicine: State of the science, implications for practice. Journal of the American Board of Family Practice, 16, 131-147.

6. Curry, L. A., \& Maniar, S. D. (2003). Academic course combining psychological skills training and life skills education for university students and student-athletes. Journal of Applied Sport Psychology, 15, 270-277.

7. Curry, L.A., \& Maniar, S. D (2004). Academic course for enhancing student-athlete performance in sport. The sport Psychologist, 18, 297- 316.

8. Tursi, D., Napolitano, S., Polidoro, L., \& Raiola, G. (2013). Video analysis as an instrument in juvenile soccer training. Journal of Human Sport and Exercise, 8 (3 PROC), S688 - S693 doi: 10.4100/jhse.2013.8.Proc3.15

9. Tursi, D., Napolitano, S., Di Tore, P.A., \& Raiola, G. (2013). Arm stroke: A comparative analysis between competitive swimming and water polo athletes. Journal of Human Sport and Exercise, 8(2 SUPPL), 314 - 322 doi: 10.4100/jhse.2012.8.Proc2.34

10. Hughes, M., \& Franks, I. (2008). Notational Analysis of Sport: Systems for Better Coaching and Performance in Sport, Routledge.

11. Napolitano, S., Di Tore, A., \& Raiola, G. (2012), Tactical analysis on 9 women water polo methodes during the 2011/12 regular season, op - bn07, 17thAnnual Congres of the ECSS - Bruges - ISBN 978-90902686-8-2

12. Hughes, M. (2004). "Notational analysis - a mathematical perspective" International Journal of Performance Analysis in Sport 4(2), 97-139.

13. Hughes, M. (2007). The essentials of performance analysis: an introduction, Taylor \& Francis.

14. Raiola, G, \& Di Tore, A. (2011) Applied Regression Analysis: study about the incidence of communication skills on the results of volleyball matches over a full season. Scientific Report Series Physical Education and Sport 1, Pitesti, Romania.

15. Napolitano, S., Tursi, D., \& Raiola, G. (2013). Water polo women's pattern tactical experience of an italian team. Journal of Human Sport and Exercise, 8(3 PROC), 660 - 670 doi: 10.4100/jhse.2013.8.Proc3.12

16. Napolitano, S., Tursi, D., Di Tore, P.A., \& Raiola, G. (2013). Tactics-based water polo training. Journal of Human Sport and Exercise, 8(2), 271 - 282 doi: 10.4100/jhse.2012.8.Proc2.29 